\title{
SURGICAL MANAGEMENT OF PLEUROPULMONARY TUBERCULOSIS
}

Jérôme Mouroux, MD ${ }^{\mathrm{a}}$

Joseph Maalouf, $\mathrm{MD}^{\mathrm{a}}$

Bernard Padovani, $\mathrm{MD}^{\mathrm{b}}$

Christine Rotomondo, $\mathrm{MD}^{\mathrm{a}}$

Henri Richelme, $\mathrm{MD}^{\mathrm{a}}$
To define the current indications for surgical management of pleuropulmonary tuberculosis and analyze the results of operative procedures, the records of 59 patients operated on between January 1987 and December 1993 were reviewed. Three patient categories were defined. Group I patients $(n=25)$ underwent operation for diagnostic purposes: solitary mediastinal node or mediastinal adenopathy associated with pulmonary lesions $(n=$ 10), pulmonary infiltrates $(n=4)$, pulmonary nodules or masses $(n=10)$, or chronic pleurisy $(n=1)$. Postoperative mortality and morbidity rates in this group were both $4 \%$. Group II patients $(n=18)$ underwent operation for active lesions: intrapulmonary cavity $(n=6)$, destroyed lung parenchyma $(n=6)$, or chronic loculated pleural effusion $(n=6)$. Postoperative morbidity and mortality rates were $16.6 \%$ and $5.5 \%$, respectively. Group III patients ( $n=16$ ) underwent operation for a complication of therapy or for sequelae of previously "cured" tuberculosis: calcified pyothorax $(n=8)$, empyema $(n=2)$, fistulized nodes $(n=2)$, bronchiectasis $(n=3)$, or aspergilloma $(n=1)$. Morbidity and mortality rates in this group were $31.25 \%$ and $12.5 \%$, respectively. Surgery continues to have both diagnostic and therapeutic indications for management of pleuropulmonary tuberculosis, despite the morbidity and mortality rates associated with operative procedures. (J THORAC CARDIOVASC SURG 1996;111:662-70)
$S^{\text {in }}$ nce the introduction of antitubercular drugs, the surgical procedures historically performed to cure tuberculosis, ranging from artificial pneumothorax to thoracoplasty, have been relegated to the secondary role of palliating the insufficiencies of medical therapy. In our geographic area, however, demographics are such that we are treating surgically both elderly patients with therapeutic sequelae of tuberculous lesions and increasing numbers of tuberculous patients coinfected with the human immunodeficiency virus (HIV). This study was performed to determine the current indications for and results of surgical management of pleuropulmonary tuberculosis.

\section{Patients and methods}

This retrospective chart review covered 59 patients (35 men and 24 women) with a mean age of 56 years (range 17

From the Service de Chirurgie Abdominale et Thoracique and the Service de Radiologie, ${ }^{\text {b }}$ Hôpital Pasteur, Nice, France.

Received for publication Sept. 28, 1994; accepted for publication May 10, 1995.

Address for reprints: Jérôme Mouroux, MD, Service de Chirurgie Abdominale et Thoracique, Hôpital Pasteur, B.P. 69, 06002 Nice Cedex, France.

Copyright $@ 1996$ by Mosby-Year Book, Inc.

$0022-5223 / 96 \$ 5.00+0 \quad \mathbf{1 2 / 1 / 6 6 2 3 1}$ to 82 years) operated on between January 1987 and December 1993 for active tuberculosis or complications of tuberculosis (Table I). Only patients with lesions caused by $\mathrm{Myco}$ bacterium tuberculosis were included. Patients were subdivided into three categories. Group I consisted of 25 patients for whom surgical intervention had a diagnostic purpose; diagnosis of tuberculosis was confirmed by histopathologic demonstration of caseous necrosis or bacteriologic examination (smears or cultures) demonstrating $M$. tuberculosis. Group II patients $(n=18)$ underwent operations for active tuberculous lesions during the course of medical therapy. Group III consisted of 16 patients who underwent operation for complications related to inactive, previously "cured" tuberculosis. Records were reviewed for age, sex, ethnic origin, HIV serologic results, history, clinical symptoms, lesions, surgical procedures, and postoperative events. The long-term outcome after operation was determined from records of follow-up visits at our institution or data provided by the patient's private physician. Two patients were unavailable for follow-up. The outcomes of the 57 other patients are known, with a minimum follow-up period of 6 months (range 6 to 84 months).

\section{Results}

Group I. The 25 patients in group I (14 men and 11 women) had a mean age of 56.8 years (range 17 to 80 years). Ten patients were immigrants (from northern Africa and southeast Asia). Six patients were HIV-seropositive and 10 others had various 
Table I. Clinical summary

\begin{tabular}{|c|c|c|c|c|c|}
\hline $\begin{array}{l}\text { Number of } \\
\text { patients }\end{array}$ & Presenting features & Lesions & Procedures & Deaths & Complications \\
\hline \multicolumn{6}{|l|}{ Group I } \\
\hline 10 & $\begin{array}{l}\text { Asthenia (3); fever (3); } \\
\text { cervical swelling (1); } \\
\text { radiologic findings (4) }\end{array}$ & $\begin{array}{l}\text { Adenopathies: mediastinal (8); } \\
\text { cervicomediastinal (1), with } \\
\text { upper lobe infiltrates (1) }\end{array}$ & $\begin{array}{l}\text { Mediastinoscopy (9); } \\
\text { cervicotomy (1) (biopsies) }\end{array}$ & 0 & 0 \\
\hline 4 & $\begin{array}{l}\text { Dyspnea (3); radiologic } \\
\text { findings (1) }\end{array}$ & Interstitial pneumonitis & Lung biopsies & 1 & 0 \\
\hline 10 & $\begin{array}{l}\text { Radiologic findings (4); } \\
\text { asthenia (2); fever (2); } \\
\text { chest pain (2); } \\
\text { hemoptysis (2) }\end{array}$ & Nodule (7); cavitary nodule (3) & $\begin{array}{l}\text { Lobectomy (6); wedge } \\
\text { resection (4) }\end{array}$ & 0 & 1 (pneumonia) \\
\hline 1 & Chest pain, asthenia & Chronic pleural effusion & Pleural and lung biopsies & 0 & 0 \\
\hline \multicolumn{6}{|l|}{ Group II } \\
\hline 6 & $\begin{array}{l}\text { Empyema (5); with } \\
\text { subcutaneous abscess (1) }\end{array}$ & $\begin{array}{l}\text { Chronic loculated pleural } \\
\text { effusion (6) }\end{array}$ & $\begin{array}{l}\text { Decortication (5); } \\
\text { drainage (1) }\end{array}$ & 0 & 0 \\
\hline 2 & Hemoptysis & $\begin{array}{l}\text { Lesions in } 1 \text { lobe (1); } \\
\text { in } 1 \text { lung (1) }\end{array}$ & $\begin{array}{l}\text { Lobectomy (1); } \\
\text { pneumonectomy (1) }\end{array}$ & 0 & 0 \\
\hline 5 & MT-positive (5) & Cavitary lesion & Lobectomy (5) & 0 & $\begin{array}{l}1 \text { (prolonged } \\
\text { air leak) }\end{array}$ \\
\hline 5 & $\begin{array}{l}\text { MT-positive (4); worsening } \\
\text { clinical status }\end{array}$ & Destroyed lung & $\begin{array}{l}\text { Pncumonectomy (3); } \\
\text { pleuropneumonectomy (2) }\end{array}$ & 1 & $\begin{array}{l}2 \text { (hemorrhage, } \\
\text { phlebitis) }\end{array}$ \\
\hline \multicolumn{6}{|l|}{ Group III } \\
\hline 8 & Infection & Calcified pyothorax & $\begin{array}{l}\text { Decortication (5); } \\
\text { Pleuropneumonectomy (2); } \\
\text { Pleurolobectomy (1) }\end{array}$ & 0 & $\begin{array}{l}5 \text { (3 prolonged } \\
\text { air leak; } \\
1 \text { empyema; } \\
1 \text { acute lung } \\
\text { edema) }\end{array}$ \\
\hline 2 & Infection & Empyema & $\begin{array}{l}\text { Drainage-irrigation (2); } \\
\quad+\text { thoracostomy }(1)\end{array}$ & 1 & 0 \\
\hline 2 & Hemoptysis & Fistulized adenopathies & Nodal excision & 0 & 0 \\
\hline 3 & $\begin{array}{l}\text { Recurrent infections ( } 3 \text { ) } \\
\text { hemoptysis ( } 3 \text { ) }\end{array}$ & Bronchiectasis & $\begin{array}{l}\text { Lobectomy (2); } \\
\text { pneumonectomy (1) }\end{array}$ & 1 & 0 \\
\hline 1 & Hemoptysis & Aspergilloma & Lobectomy (1) & 0 & 0 \\
\hline \multicolumn{6}{|l|}{ Total } \\
\hline 59 & & & & $4(6.7 \%)$ & $9(15.25 \%)$ \\
\hline
\end{tabular}

MT, M. tuberculosis.

risk factors for active tuberculosis: smoking $(n=4)$, kidney transplantation $(n=1)$, diabetes $(n=1)$, obstructive bronchopulmonary disease $(n=2)$, or cancer $(n=2)$. Tuberculosis was suspected in nine patients $(36 \%)$, but results of routine diagnostic procedures (search for $M$. tuberculosis in sputum samples or bronchial washings, transbronchial biopsy) were negative. In nine cases (36\%), operation was prompted by suspicion of a primary or secondary malignancy. No presumptive diagnosis was made in the other cases.

Ten patients (including four who were seropositive for HIV) had mediastinal or cervicomediastinal adenopathy, either a solitary node $(n=9)$ or nodes associated with an upper pulmonary lobe infiltrate $(n=1)$. These patients underwent nodal biopsy by mediastinoscopy $(n=9)$ or cervicotomy $(n=1)$.
Four patients (including two who were seropositive for HIV) had a diffuse pulmonary infiltrate; lung biopsies were performed by thoracotomy $(n=2)$ or video-assisted thoracoscopy $(n=2)$. Ten patients had nodules or parenchymal masses, including three cavitary lesions. Five of these 10 patients had previously undergone noncontributory computed tomography-guided percutaneous needle aspiration. Treatment consisted of wedge resection or lobectomy, depending on lesion site and diameter; surgical resection was performed by thoracotomy $(n=8)$ or video-assisted thoracoscopy $(n=2)$. One patient with chronic pleurisy underwent video-assisted thoracoscopic lung and pleural biopsy.

Mortality and morbidity rates in this group were both $4 \%$. The only death occurred in a 78 -year-old patient who underwent lung biopsy by thoracotomy 
after admission for acute febrile respiratory failure. Deterioration of his condition, despite administration of nonspecific antibiotic therapy and negative results of bacteriologic cultures, prompted surgical biopsy, which established a diagnosis of miliary tuberculosis. Death occurred from respiratory failure refractory to therapy postoperative day 10 .

The nonimmunodepressed patients in the remaining group of 24 survivors were placed on the classic 6-month treatment regimen used in France; this protocol consists of a four-drug regimen (rifampin, isoniazid, ethambutol, and pyrazinamide) for 2 months, followed by a two-drug regimen (rifampin and isoniazid) for 4 months. The HIV-seropositive patients in this group were treated for 9 months (four drugs for 3 months and then two drugs for 6 months). The outcome was favorable for all 24 patients, regardless of immune status. Three HIVseropositive patients died 18,36 , and 50 months after diagnosis of tuberculosis, but these deaths were not caused by disease reactivation.

Group II. Group II consisted of 18 patients (11 men and 7 women) with a mean age of 47.5 years (range 23 to 80 years). Seven were immigrants (from northern Africa and Romania) and seven had risk factors for active tuberculosis: alcoholism and smoking $(n=5)$ or obstructive bronchopulmonary disease $(n=2)$. The initial treatment and follow-up of these patients were managed by our institution's Pneumology Department. None of these patients had ever had a strain of $M$. tuberculosis resistant to the antitubercular drugs used.

Eight patients required operation for a complication during medical therapy that had been followed correctly for 1 to 6 months; four were on a four-drug regimen (rifampin, isoniazid, ethambutol, and pyrazinamide) and the other four were on a two-drug regimen (rifampin and isoniazid). Five patients with empyema were treated by pleural decortication. One patient had a pleuroparietal cold abscess; the lesion was opened and the pleural cavity was treated by drainage and irrigation. Repeated episodes of hemoptysis in two patients necessitated lobectomy $(n=1)$ or pneumonectomy $(n=1)$.

Ten patients underwent operation because of the inefficacy of medical management. Five of these had a tuberculous cavity in a single lobe; direct sputum smears demonstrated $M$. tuberculosis in all cases, despite apparent compliance with treatment (fourdrug regimen) for 3 to 7 months. All five patients underwent lobectomy. After operation, a prolonged air leak (14 days) without any demonstrable bron- chial fistulas developed in one patient. Histopathologic examination of the surgical specimens demonstrated active tubercular lesions in all cases. One patient had coexistent adenocarcinoma. Five patients had diffuse lesions in a single lung, corresponding to destroyed lung parenchyma; two had complied with the four-drug regimen for 3 and 6 months. The other three patients, who had been treated for 8,12 , and 15 months, admitted having taken their treatment only sporadically. All five patients had a deterioration in general condition, with loss of $5 \%$ to $20 \%$ of initial weight; two patients had several bouts of hemoptysis. Direct sputum smears showed $M$. tuberculosis for four patients. Procedures consisted of pneumonectomy $(n=3)$ and, for the two patients whose disease had been active for 12 and 15 months, extrapleural pneumonectomy. A 75-year-old patient treated by extrapleural pneumonectomy died on postoperative day 5 of multiple organ failure; another patient had hemorrhage in the chest cavity necessitating thoracotomy for clot evacuation. One patient had lower limb phlebitis, which had a favorable outcome. Histopathologic examination of the resected specimens revealed active tubercular lesions, bronchial dilatation, and scleroemphysema of varying severity.

Overall mortality and morbidity rates in Group II were $5.5 \%$ and $16.6 \%$, respectively. Regardless of the indication for operation, all survivors were discharged after operation on a four-drug regimen. The decision to switch to a two-drug regimen, which was based on clinical status or negative results of sputum examinations, was made between postoperative months 3 and 6 . The total duration of treatment varied from 9 to 12 months. Two patients died of unrelated causes 12 and 32 months after operation; the others have had favorable outcomes regardless of ethnic origin.

Group III. The 16 patients in group III (10 men and 6 women) had a mean age of 65 years (range 44 to 82 years). Two patients had diabetes, one had adrenal insufficiency, and two had alcoholism and smoked.

Eight of these 16 patients had a calcified pyothorax after artificial pneumothorax $(n=6)$ performed a mean of 32 years earlier (range 23 to 44 years) or tuberculous pleurisy $(n=2)$ treated 12 and 24 years previously. Operation was prompted by recurrent infections. Five patients underwent drainage-irrigation of the cavity (duration 8 to 19 days) before operation. Bacteriologic cultures grew M. tuberculosis $(n=1)$, Staphylococcus aureus $(n=3)$, Es- 
cherichia coli $(n=1)$, or Streptococcus species $(n=$ 1). One patient had multiple organisms (Streptococcus species, Bacteroides fragilis, Enterobacter cloacae). The procedures consisted of decortication $(n=5)$, pleuropneumonectomy $(n=2)$, or pleurolobectomy $(n=1)$. After operation, three patients had a prolonged air leak (10 to 21 days after decortication); one patient had a pyothorax after extrapleural pneumonectomy without fistulization, which was successfully treated by drainage-irrigation; another patient had acute lung edema, which resolved with treatment.

Two patients had empyema after pneumonectomy performed 27 years earlier for tuberculosis; neither had a bronchopleural fistula. Infection of the pneumonectomy cavity in one patient was caused by $S$. aureus; treatment consisted of drainage-irrigation and appropriate antibiotics. This patient had a favorable course. The second patient had an infection of the pneumonectomy cavity caused by $M$. tuberculosis; specific antibiotics and drainage-irrigation failed to sterilize the cavity and thoracostomy proved necessary. Despite a favorable local course, this patient had a severe depressive syndrome and committed suicide after 45 days of treatment.

Three patients who had been treated for tuberculosis 14,15 , and 18 years earlier had bronchiectasis involving the upper right lobe $(n=1)$, the middle lobe $(n=1)$, or the right lung $(n=1)$. The indication for operation was recurrent infections, which were always associated with hemoptysis. One of these patients, who was treated by pneumonectomy, died on postoperative day 4 of a pulmonary embolus.

Two patients who had been treated for tuberculosis 3 and 5 years earlier had calcified adenopathy with bronchial fistulization, which manifested as episodes of hemoptysis. Fiberoptic bronchoscopy visualized a calcified node in a fistulous orifice in both cases (2 and $3 \mathrm{~mm}$ diameter fistulas, at the origin of the right superior lobar bronchus and on the intermediate bronchus). Surgical intervention consisted of resection of the node and suture of the communication.

Three years after therapy for tuberculosis, one patient had an aspergilloma in a sterilized cavity (free of $M$. tuberculosis) in the upper left lobe; this lesion was responsible for hemoptysis. Treatment consisted of lobectomy.

After operation, a classic antituberculosis regimen (four-drug then two-drug regimen) was prescribed for 6 months for the seven patients in whom
M. tuberculosis was identified as well as for those patients who had never received a complete antituberculosis treatment at the time of initial diagnosis. The other patients were treated empirically with a two-drug regimen for 4 months.

Three deaths occurred at long term; two patients died of unrelated causes 24 and 48 months after operation. The third patient had undergone extrapleural pneumonectomy, but complete removal of the calcified capsule had proved impossible. Despite successful management of a recurrent infection of the cavity 6 months later by drainageirrigation, shortly thereafter a new infection was responsible for the patient's death.

\section{Discussion}

Historically, surgery has played a major role in the treatment of pleuropulmonary tuberculosis. During the first half of this century, a number of techniques were developed for collapse therapy, ranging from intrapleural pneumothorax to thoracoplasty. Treatment was designed to allow the tuberculous lesions to rest by eliminating the elastic forces of the lung that kept the cavities open. A stay at a sanatorium complemented these procedures. In 1944, the discovery of streptomycin modified the therapeutic protocol while leaving a place for collapse therapy and surgical resection. Starting in the 1960s, rifampin and other antitubercular drugs radically transformed the prognosis of the disease, and surgery was relegated to a secondary role for the treatment of complications.

The increasing incidence of acquired immunodeficiency syndrome and its recognized association with the resurgence of tuberculosis underscores the need for young surgeons to remain aware of the surgical techniques for management of tuberculosis and its sequelae. ${ }^{1-4}$ To determine the current role of surgery, procedures performed for diagnostic purposes (group I, 25 patients, $42.4 \%$ ) were analyzed separately from therapeutic procedures for active lesions (group II, 18 patients, $30.5 \%$ ) or complications (group III, 16 patients, $27.1 \%$ ).

Diagnostic surgical procedures continue to play an important role, despite modern diagnostic techniques. As in the past, operation is indicated for potentially neoplastic lesions (pulmonary masses or nodules), ${ }^{5,6}$ which accounted for $36 \%$ of the cases in group I. As emphasized by other authors, percutaneous needle aspiration appears to be of limited value in these cases. ${ }^{6}$ Our series was particular in that operations were also performed for lesions with 
unusual radiologic and clinical characteristics (solitary adenopathy, interstitial pneumonitis) for which a diagnosis of tuberculosis is not always entertained. These atypical clinical lesions, first reported some 10 years ago, ${ }^{3}$ are observed especially in HIV-seropositive patients at an advanced stage of disease (CD4 $<200$ cells $\left./ \mathrm{mm}^{3}\right)^{7,8}$ The particular clinical and radiologic features become increasingly atypical: equal frequency of distribution between the upper and lower lobes, lack of excavation, mediastinal adenopathy (solitary or multiple nodes), associated pleural effusions, and high frequency of extrapulmonary dissemination. ${ }^{9-11}$

Diagnostic interventions include biopsy (nodal, pulmonary, or pleural) and resection. Mediastinoscopy is the most commonly used method (nine cases) for biopsy of mediastinal nodes. Lung and pleural lesions are often amenable to video-assisted thoracoscopy, a recent technique that we have used on five occasions since 1991. Less aggressive than thoracotomy, and thus more easily accepted by patients, video-assisted thoracoscopy is particularly suitable for lung or pleural biopsies because the only potential difficulty is a dense symphysis, which can interfere with or prevent successful examination. ${ }^{12-14}$ In patients with nodular lesions, videoassisted thoracoscopy is reserved for peripheral nodes at least $3 \mathrm{~cm}$ in diameter, which can usually be managed by wedge resection. By contrast, for central and especially large lesions, which generally require lobectomy, we still prefer thoracotomy. Extemporaneous examination always remains indispensable to rule out an associated neoplasm (one case in our series). The cost effectiveness of these diagnostic procedures and the current possibilities of video-assisted thoracoscopy should help eliminate diagnostic delays.

Although surgery is theoretically of limited value in cases of active disease, it was indicated in two circumstances in our study: (1) treatment of a complication $^{15}$ despite compliance with medical treatment (persistent or recurrent hemoptysis [two cases], empyema [five cases], or cold abscess [one case]) or (2) no response to medical therapy (10 cases).

Infections in some certain patients demonstrate true primary resistance to classically used antibiotics. This situation has been reported in certain urban areas of the United States. A 1991 study in New York City, for example, mentioned a primary resistance rate of $23 \%$. In that study, $33 \%$ of the 466 strains tested were resistant to at least one antitu- bercular drug, and $19 \%$ were resistant to isoniazid and rifampin. ${ }^{16}$

Multidrug resistance is favored by a number of factors, including poorly conducted previous therapy, coinfection with HIV, and intravenous use of illicit drugs. In these situations, Iseman and colleagues ${ }^{17}$ demonstrated the complementary role of surgery in selected patients. In their study, 29 of 99 patients with drug-resistant disease were selected for surgical treatment, and 25 of the 27 survivors had a favorable course with negative results of sputum examinations after treatment. ${ }^{17}$

The current situation in France is somewhat different, because primary resistance rates during the same period as the study by Iseman and colleagues were only $6 \%$ for streptomycin, $2 \%$ for isoniazid, and less than $1 \%$ for rifampin, ethambutol, and pyrazinamide. ${ }^{18}$ Our experience differs from that of these U.S. authors because we never encountered any $M$. tuberculosis strain resistant to the drugs used during follow-up of our patients.

In our series, operations were performed in two situations: (1) persistent $M$. tuberculosis on direct sputum examination after at least 3 months of a 4-drug regimen (drug efficacy was verified by susceptibility testing) or (2) clinical and radiologic demonstration of progressive disease. These cases can be explained by two mechanisms: existence of specific focal or diffuse lesions (tuberculoma or cavities) acting as reservoirs for the tubercle bacilli where diffusion of antibiotics is poor (seven patients; Fig. 1) or poor therapeutic compliance with interruption of or intermittent drug intake (3 patients). In these situations, as in cases of true drug resistance as reported by Iseman and colleagues ${ }^{17}$ resection of major lesions can favor the action of the antibiotics on other disease sites. ${ }^{19}$ After operation, treatment was continued in our patients for 9 to 12 months; continuation for 18 to 24 months is advisable in case of true drug resistance. ${ }^{17}$ Our results, like those of Iseman and colleagues, ${ }^{17}$ clearly demonstrate the complementary role of surgery in the treatment of patients with resistant disease.

The most common procedures for active lesions involve parenchymal resection (segmentectomy, lobectomy, or pneumonectomy). Of the various "classic" interventions (speleotomy, phrenic nerve crush, thoracoplasty), only thoracoplasty retains a role as a complement to resection or decortication. ${ }^{20} \mathrm{Be}$ cause of the complementary nature of resection for treatment of tuberculosis, the procedure must be adapted (1) to the location and extent of major 


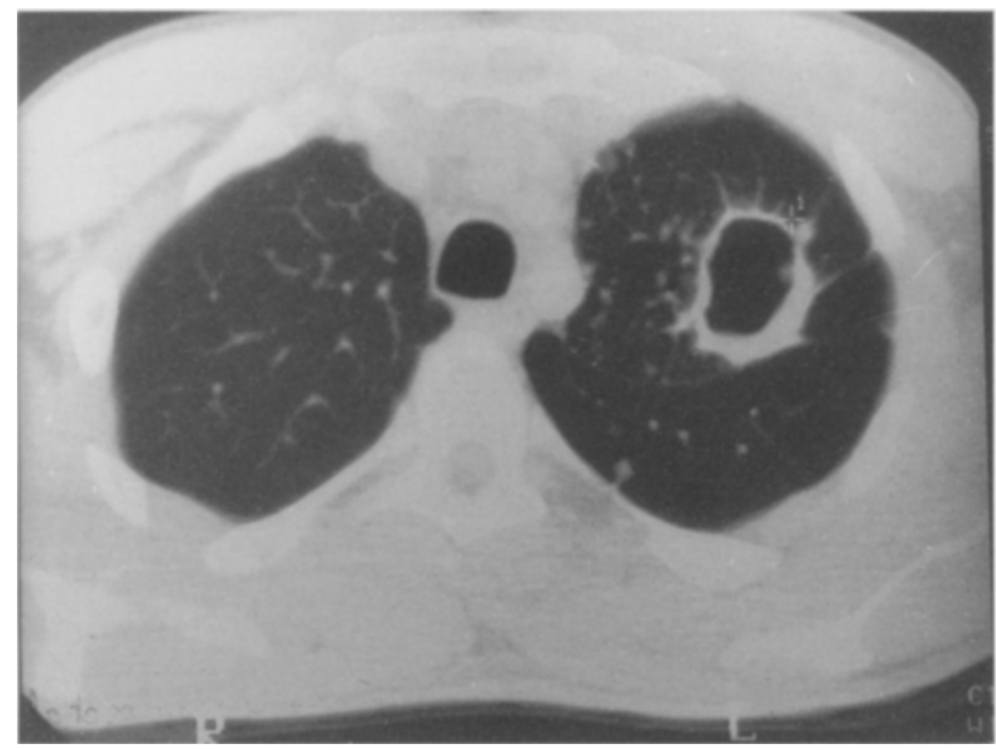

Fig. 1. A 35-year-old prison inmate with persistent $M$. tuberculosis in sputum despite 3 months of therapy. The computed tomographic chest scan revealed a cavity, which was managed by lobectomy, in the upper left lobe.

lesions (this is best evaluated by computed tomographic scans), (2) to the patient's ventilatory reserve, and (3) to the functional value of the parenchyma scheduled for resection, as determined by ventilation and perfusion radionuclide lung scans. In our series, we were able to limit resection to lobectomy in six cases. In five patients, the extent of lesions necessitated pneumonectomy; two patients whose disease had been active for longer than a year had extensive pleuropulmonary adhesions that led to extrapleural pneumonectomy. The postoperative courses of these patients (one death, one hemorrhage) reflect the severity of these procedures, which in our opinion should be considered only when absolutely necessary. A number of technical issues merit discussion. (1) Selective tracheobronchial intubation and ventilatory exclusion before the patient is placed in the lateral decubitus position reduces the risk of contamination of the contralateral lung. (2) Pedicular dissection can be complicated by the existence of large inflammatory nodes and must be performed prudently. Reed, Parker, and Crawford ${ }^{15}$ reported a case of laceration of the right pulmonary artery during an upper lobectomy. (3) In case of severe infection, certain authors report covering the suture with a muscle flap to reduce the risk of fistulization, ${ }^{17}$ but we have never used this technique. (4) Because of the possibility of insufficient reexpansion of the residual lung parenchyma after lobectomy, thoracoplasty has been proposed during the same operative session. ${ }^{21} \mathrm{Al}-$ though we agree that such an approach may be indicated when there is a large difference in volume between the pleural cavity and the residual parenchyma, in other situations it is better to let the residual tissues expand after operation, if necessary with the help of physical therapy and pneumoperitoneum. If thoracoplasty still proves necessary after 4 to 8 weeks, it is easier to determine the exact extent needed. ${ }^{20}$

Our last group of patients all had complications of tuberculosis or previous therapy. Although such sequelae generally remain clinically silent and require only surveillance and occasionally medical therapy, operation is necessary for infectious or hemorrhagic complications. A number of the complications treated surgically in this group have been reported frequently in other studies $5,6,15$ : empyema, bronchiectasis, adenopathy with fistulization, and parenchymal cavity with aspergilloma (Fig. 2). Our series is notable because of the relatively elevated number of patients with infected calcified pleural cavities caused by therapeutic pneumothorax (one third of the patients in group III, $10 \%$ of the series; Fig. 3). This can be partially explained by the fact that therapeutic pneumothorax was used in France 


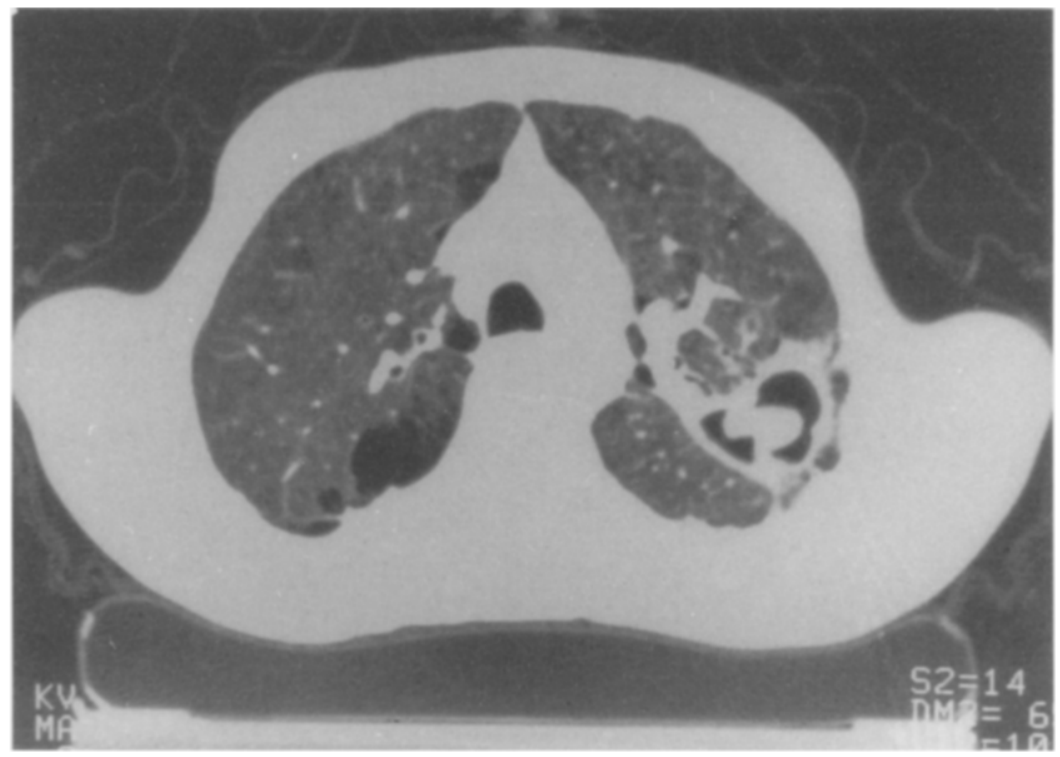

Fig. 2. This 52-year-old patient who had been treated 3 years earlier for tuberculosis had recurrent hemoptysis. The computed tomographic chest scan demonstrated an aspergilloma in a sterilized cavity (sterilized by treatment) that was treated by lobectomy.

until fairly recently (one patient in this series underwent pneumothorax in 1965). In addition, our region is home to numerous elderly persons. This type of sequela, like those associated with pleurisy (two cases), can arise through infection by the subjacent parenchyma (bronchopleural fistula) or less often through hematogenous spread from an extrathoracic lesion. ${ }^{22,23}$ The causative organisms are usually nonspecific ( $S$. aureus was cultured in three of seven patients in this series), but $M$. tuberculosis is also encountered (one patient).

The radiologic and clinical manifestations are variable: persistent, long-term fever, progressive deterioration of general condition, and modification of the radiologic appearance of pleural sequelae (increase in size, presence of an air-fluid level). Patient age and loss of respiratory capacity as a result of previous therapy explain why operation is indicated only as a last resort. Nevertheless operation remains the only radically effective treatment method. Preoperative workup must guide selection of the method best suited to the patient's condition and pleuropulmonary lesions. Computed tomography is a valuable complement to routine examinations such as fiberoptic bronchoscopy, spirometry, and radionuclide studies. This imaging technique can evaluate the dimensions of the pleural cavity, allow prediction of any operative difficulties, and demon- strate the extent and the quality of the subjacent parenchyma before operation, local preparation of the purulent cavity by drainage-irrigation should be performed to reduce the risks of postoperative suppuration (this was performed for five patients in our series). During this period, patients benefit from appropriate antibiotics, respiratory preparation, and (eventually) nutritional support. The ideal surgical treatment of these pleural cavities remains decortication, sometimes associated with limited resection (performed in six patients in our series); authors with considerable experience with this surgical technique have reported good results. ${ }^{23-25}$ Extrapleural pneumonectomy is sometimes required to resect the pleural cavity and the subjacent destroyed lung parenchyma (two cases in our series). The risks of these procedures, discussed in connection with the treatment of active lesions, should limit their use to certain carefully selected cases. ${ }^{23}, 26$ When these radical methods are not feasible because of patient age, general condition, or functional status, percutaneous drainage (sometimes definitive), thoracostomy, or various techniques of collapse therapy may be attempted. ${ }^{27-30}$

All of the patients in group III were given antitubercular drugs after operation, even though we are unaware of any study validating this approach other than for those who have positive results of $M$. 


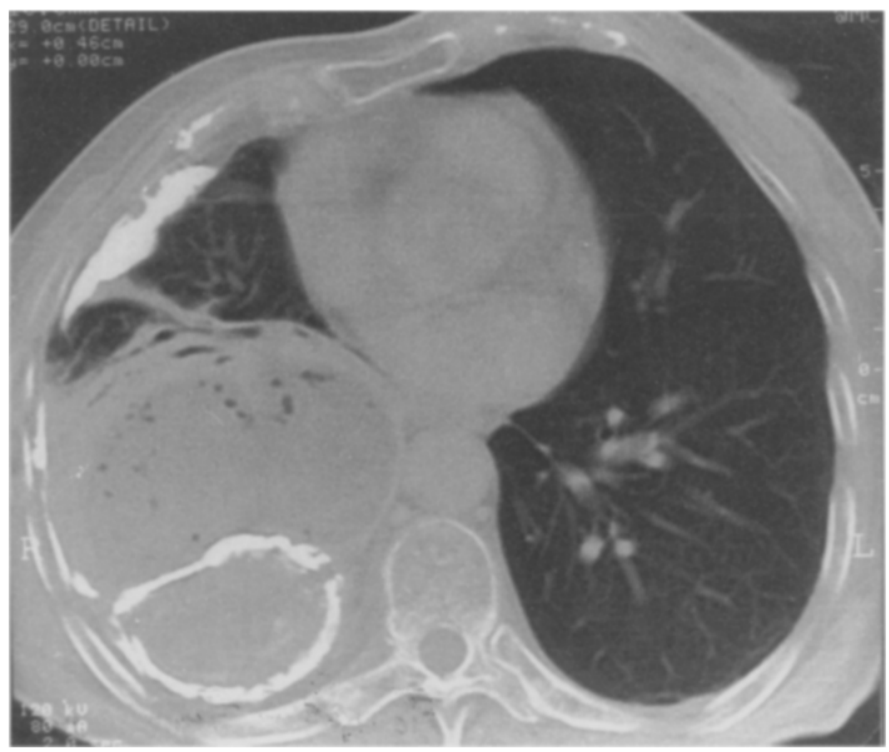

Fig. 3. This 70 -year-old patient treated by pneumothorax for tuberculosis in 1955 had recurrent infections. The calcified pyothorax, which contained scattered, bubblelike gas density images visualized by computed tomographic chest scans, was successfully treated by decortication.

tuberculosis testing. The belief that surgical manipulations and associated trauma may reactivate foci of bacilli was the rationale for this decision.

Overall, our results are less favorable than those of other recent series, in which mortality was nil. ${ }^{6,15}$ Iseman and colleagues ${ }^{17}$ reported two deaths among their 29 patients, but these deaths were not related to operation or tuberculosis. When diagnostic procedures are analyzed separately, however, the mortality rate in our series $(4 \%)$ concurs with literature data $^{5,6,15}$; the death in this group was directly attributable to the severity of the patient's initial condition rather than to the surgical procedure. In contrast, our results with surgical management of active lesions (mortality rate of $5.5 \%$ and morbidity rate of $12.5 \%$ ) and complications (mortality rate of $12.5 \%$ and morbidity rate of $31.2 \%$ ) appear to be directly related to both the patient's condition and the extent of the intervention. Surgical treatment continues to involve considerable risks for this population, and radical interventions such as extrapleural pneumonectomy should be reserved for a highly select group of patients in cases of strict necessity. tion.

We thank Nancy Rameau for assistance with transla-

\section{REFERENCES}

1. Molinard M, Hirsch A, Chrétien J. La tuberculose: une nouvelle priorité. Presse Med 1994;23:1166-71.
2. Groupe d'etude et de traitement des infechones á mycobacteries résistantes. Augmentation des cas de tuberculose dans trois hôpitaux parisiens [Letter]. Presse Med 1988; $17: 1859$.

3. Langlade LA, Meissner M, Nolan C, Ashbaugh DG. Tuberculosis and the surgeon. Am J Surg 1992,163-505-9.

4. Theuer CP. Tuberculosis in patients with human immunodeficiency virus infection: review of current concepts. West J Med 1989;150:700-4.

5. Neptune WB, Kim S, Bookwalter J. Current surgical management of pulmonary tuberculosis. $J$ THORAC CARDIOVASC SURG 1970;60:384-91.

6. Whyte RI, Deegan SP, Kaplan DK, Evans CC, Donnelly RJ. Recent surgical experience for pulmonary tuberculosis. Respir Med 1989;83:357-62.

7. Meduri UG, Stein DS. Pulmonary manifestations of acquired immunodefiency syndrome. Clin Infect Dis 1992;14:98-113.

8. Murray JF, Mills J. Pulmonary infectious complications of human immunodeficiency virus infection. Am Rev Respir Dis 1990;141:1356-72.

9. Perronne $C$, Zharaoui $M$, Leport $C$, et al. Tuberculose chez les malades infectés par le virus de l'immunodéficience humaine: trente observations. Presse Med 1988;17:1479-83.

10. Long R, Maycher B, Scalani, et al. The chest roentgenogram in pulmonary tuberculosis patients seropositive for HIV type 1. Chest 1991;99:123-7.

11. Mouroux J, Riquet M, Rotomondo C, et al. In: Champault G, Bourgeon A, eds. SIDA et chirurgie. Paris: Springer-Verlag, 1993:43-58.

12. Mouroux J, Maalouf J, Bernard JL, et al. Chirurgie thoracique vidéo-assistée: indications et limites. Ann Chir 1994; 48:37-42.

13. Ferson PF, Landreneau RJ, Dowling RD, et al. Comparison of open versus thoracoscopic lung biopsy for diffuse infiltra- 
tive pulmonary disease. J Thorac Cardiovasc Surg 1993; 106:194-9.

14. Landreneau RJ, Hazelrigg SR, Ferson PF, et al. Thoracoscopic resection of 85 pulmonary lesions. Ann Thorac Surg 1992;54:415-20.

15. Reed CE, Parker EF, Crawford FA Jr. Surgical resection for complications of pulmonary tuberculosis. Ann Thorac Surg 1989;48:165-7.

16. Freden TR, Sterling T, Mendez AP, Jilburn JO, Cauthen GM, Dooley SW. The emergence of drug-resistant tuberculosis in New York City. N Engl J Med 1993;328:521-6.

17. Iseman MD, Madsen L, Goble M, Pomerantz M. Surgical intervention in the treatment of pulmonary disease caused by drug-resistant Mycobacterium tuberculosis. Am Rev Respir Dis 1990;141:623-5.

18. Bicart-See A, Marchou B. Tuberculose: une leçon d'humilité. Lett Infectiol 1993;8:589-92.

19. Delarue NC, Gale G. Surgical salvage in pulmonary tuberculosis. Ann Thorac Surg 1974;18:38-51.

20. Hopkins RA, Ungerleider RM, Staub EW, Young WG. The modern use of thoracoplasty. Ann Thor Surg 1985;40:181-7.

21. Megevand RP, Cherkaoui O, Wipf R, Stinghe R. La thoracoplastie ostéoplastique de Björk. Complément thérapeutique des résections pulmonaires partielles: a propos de 34 interventions. Ann Chir Thorac Cardiovasc 1977; $16: 444-8$

22. Neff TA, Buchanan BD. Tension pleural effusion: a delayed complication of pneumothorax therapy in tuberculosis. Am Rev Respir Dis 1975;111:543-8.

23. Langston HT, Barker WL, Graham AA. Pleural tuberculosis. J ThORAC CARDIOVASC SuRg 1967;54:511-9.

24. Toty L, Hertzog P, Personne C. Résultats du traitement chirurgical des pyothorax calcifiés. Rev Tuberc Pneumol 1969;7:905-30.

25. Merlier M, Lebrigand $H$, Rojas-Miranda A, Levasseur $P$, Luizy J. 83 cas de calcifications pleurales. Rev Tuberc Pneumol 1969;7:895-904.

26. Riquet M, Dupont P, Saab M, Debesse B. Poche pleurale calcifiée suppurée sur poumon détruit: a propos de 3 observations. Rev Gériatrie 1991;16:313-7.

27. Iioka S, Sawamura K, Mori T, et al. Surgical treatment of chronic empyema: a new one-stage operation. J THORAC CARDIOVASC SuRg 1985;90:179-85.

28. Yuste MG, Ramos G, Duque JL, Gonzalez Selma ML, Castanedo M. La thoracopleuromyoplastie comme correction définitive des empyèmes pleuraux chroniques, après préparation avec thoracostomie ouverte [English abstract]. Ann Chir 1991:45:711-4.

29. Pairolero PC, Trastek PC. Surgical management of chronic empyema: the role of thoracoplasty. Ann Thorac Surg 1990; 50:689-90.

30. Pairolero PC, Arnold PG, Pieher JM, McGoon DC. Intrathoracic tranposition of extrathoracic skeletal muscle. J THORAC CARdiovasc Surg 1983;86:809-17. 